\title{
Prediction of Combined Mesiodistal Width of Unerupted Permanent Canine and Premolars using Moyer's Mixed Dentition Analysis in Nepalese Newar Population
}

\author{
Dr Amrita Shrestha,' Dr Dilesh Pradhan² \\ Lecturer, Department of Orthodontics \& Dentofacial Orthopedics, ${ }^{2}$ Lecturer, Department of Prosthodontics \& \\ Maxillofacial Prosthesis, Kathmandu Medical college \& Teaching Hospital \\ Correspondence: Dr Amrita Shrestha; Email: amritaash@yahoo.com
}

\section{ABSTRACT}

Introduction: Moyer's probability table is most commonly used to predict the mesiodistal width of permanent canines and premolars in mixed dentition. However, the table was formulated using data from Caucasian population. This study was performed to compare the Moyer's prediction table with actual value in Nepalese Newar population as ethnicity is one of the important factor to determine teeth width.

Materials \& Method: Combined mesiodistal width of permanent canine and premolars were measured in 150 study models of Nepalese Newar orthodontic patients (75males and 75 females). The value was compared with the Moyer's prediction table at all probability level.

Result: There was no statistically significant difference between the actual combined width and that predicted from Moyer's table at $85 \%$ probability level for maxilla and at $75 \%$ level for mandible in male, at $95 \%$ probability level for maxilla and at $85 \%$ probability level for mandible in female.

Conclusion: Moyer's probability level can be used to predict the combined mesiodistal width of permanent canines and premolars in Nepalese Newar population but at specific probability level.

Keywords: Analysis, Mixed dentiotion, M-D width, Moyer's chart

\section{INTRODUCTION}

Crowding of teeth is one of the main reason for patients seeking orthodontic treatment tr-3 $^{-3}$ as it is unesthetic and maintenance of oral hygiene also becomes difficult. If it can be diagnosed early during mixed dentition stage, intervention can be done to treat or to reduce its severity. Crowding or spacing occurs due to arch length tooth material discrepancy and we have various methods available to analyze such discrepancy. ${ }^{4,5}$ Mixed dentition space analysis can be done to predict the future requirement of space for permanent teeth so that intervention can be done to reduce the severity of malocclusion. ${ }^{5,6}$

Moyers probability table is available to predict the combined width of permanent canine and premolars for both maxilla and mandible on the basis of mandibular permanent incisors. ${ }^{7}$ The sample details and regression equation used to establish the probability table are not clear in literature. According to Proffit and Fields ${ }^{1}$ Moyer's table is fairly applicable for northern European whites on which the data was based but does not accurately predict for other races. $^{8-12}$

There have been two reported studies done on Nepalese population to predict the width of permanent canine and premolars. ${ }^{10,11}$ Both studies found inaccuracy of the Moyer's prediction table when applied in Nepalese population.

Nepal is a country of ethnic diversity and Jaiswal et al ${ }^{10}$ did not take ethnic diversity into consideration and Gyawali et all did study on Nepalese Brahmin and chhetri only. Newar community form 6th largest population of the country comprising $5.4 \%$ of total population ${ }^{13}$ and although they are spread throughout the country but are mainly concentrated in Kathmandu Valley. This study aims to test the applicability of Moyer's mixed dentition analysis for Newar community in Kathmandu valley.

\section{MATERIALS AND METHOD}

This is a cross-sectional analytical study conducted in Department of Orthodontics and Dentofacial 
Orthopedics, Kathmandu Medical College - BDS program, Bhaktapur, Nepal. Study models prepared as a diagnostic record for Newar patients seeking orthodontic treatment were taken as sample.

The inclusion criteria were:

- Nepalese Newar of minimum of 14 years of age

- $\quad$ Fully erupted permanent teeth up to 1st molar on both maxilla and mandible (2nd and 3rd molars are not considered)

The exclusion criteria were:

- Interproximal caries or restoration

- Malformation of teeth

- Attrition or abrasion

- history of orthodontic treatment

- history of trauma to jaw or teeth

Total of 150 (75 males and 75 females) samples meeting all inclusion criteria were taken for the study. Mesiodistal width of mandibular incisors, maxillary and mandibular canines and premolars were measured in natural light ${ }^{5}$ using digital Vernier caliper of $0.01 \mathrm{~mm}$ accuracy. Maximum mesiodistal widths of crowns of each tooth were measured at right angle to long axis of the individual tooth ${ }^{5,8}$ with caliper beaks entering either from buccal or occlusal, preferably buccal unless tooth was rotated. Test retest reliability was done in two weeks' interval for all sample. A third measurement was done for variation of more than $0.2 \mathrm{~mm}$. Variation of $0.2 \mathrm{~mm}$ or less in repeat measurements were averaged. ${ }^{10,14}$ All the measurements were done by single investigator. Collected Data were analysed using IBM SPSS Statistics 20.

\section{RESULT}

Independent sample t-test was performed on mesiodistal dimension of teeth on right and left and it was found to be statistically insignificant for both male and female. Thus the further calculations were done taking mean for right and left.

Sum of mesiodistal width of mandibular four incisors (CWI), maxillary canine and premolars (UCW) and mandibular canine and premolars (LCW) were obtained. Independent sample t-test showed statistically significant gender variation for CWI, UCW and LCW, male having larger values as shown in table 1.

Paired sample t-test was done to find whether significant difference existed between the actual combined width of canine and first and second premolars and the predicted width using Moyer's table at different probability level for both male and female. Result is summarized in table 2 and 3. In male, Moyer's table underestimated the actual size of canine and premolars at all probability levels except at 95\% level where it overestimated for maxilla and at $95 \%$ and $85 \%$ for mandible, and the difference was statistically insignificant at $85 \%$ level for maxilla and $75 \%$ for mandible. Also in female, it underestimated the value which was statistically significant at all probability levels except at 95\% level for maxillary canine and premolars. It overestimated for mandibular teeth at $95 \%$ and $85 \%$ level. The difference was statistically insignificant at $85 \%$ level.

Linear regression equations and correlation coefficient were performed to predict the combined width of canine and premolars on maxilla and mandible using combined width of mandibular incisors. Regression parameters are summarized in table 4 . The constants for linear regression equations $(y=a+b x)$ for prediction in this study are following:

\section{For LCW}

$Y=8.59+0.563 \times($ female $)$

$Y=3.903+0.763 x$ (male)

For UCW

$Y=12.733+0.413 x$ (female)

$Y=12.159+0.453 x($ male $)$

Table 1: Descriptive Statistics for combined width of lower incisors, combined width of canine and premolars in maxilla and mandible

\begin{tabular}{|l|c|c|c|c|}
\hline Variables & Gender & Mean & SD & P value \\
\hline \multirow{4}{*}{ CWI } & M & 24.83 & 1.32 & \multirow{2}{*}{$0.000^{*}$} \\
\cline { 2 - 4 } & $\mathrm{F}$ & 23.83 & 1.79 & \\
\cline { 2 - 4 } & $\mathrm{M}+\mathrm{F}$ & 24.329 & 1.65 & \\
\hline \multirow{4}{*}{ UCW } & $\mathrm{M}$ & 23.397 & 1.01 & \multirow{2}{*}{$0.000^{*}$} \\
\cline { 2 - 5 } & $\mathrm{F}$ & 22.574 & 1.32 & \\
\cline { 2 - 5 } & $\mathrm{M}+\mathrm{F}$ & 22.99 & 1.24 & \\
\hline \multirow{3}{*}{ LCW } & $\mathrm{M}$ & 22.847 & 1.25 & \multirow{2}{*}{$0.000^{*}$} \\
\cline { 2 - 5 } & $\mathrm{F}$ & 21.998 & 1.43 & \\
\cline { 2 - 5 } & $\mathrm{M}+\mathrm{F}$ & 22.42 & 1.40 & \\
\hline
\end{tabular}

* = significant 
Table 2: The difference (in $\mathrm{mm}$ ) between the mean values of actual sum of maxillary permanent canine and first and second premolars of Nepalese Newar and those predicted from Moyers charts for the same subjects.

\begin{tabular}{|c|c|c|c|c|c|c|}
\hline Gender & Probability \% & Mean (Actual - Predicted) & SD & SEM & $95 \% \mathrm{Cl}$ & Sig. (2-tailed) \\
\hline \multirow{9}{*}{ Combined } & 95 & -0.145 & 1.031 & 0.093 & $-0.328-0.038$ & 0.120 \\
\hline & 85 & 0.4759 & 1.043 & 0.0937 & $0.29044-0.661$ & $0.000 *$ \\
\hline & 75 & 0.80 & 1.045 & 0.0938 & $0.617-0.988$ & $0.000^{*}$ \\
\hline & 65 & 1.081 & 1.062 & 0.095 & $0.892-1.269$ & $0.000^{*}$ \\
\hline & 50 & 1.434 & 1.075 & 0.097 & $1.243-1.625$ & $0.000 *$ \\
\hline & 35 & 1.812 & 1.081 & 0.097 & $1.619-2.004$ & $0.000 *$ \\
\hline & 25 & 2.085 & 1.095 & 0.098 & $1.890-2.279$ & $0.000 *$ \\
\hline & 15 & 2.424 & 1.108 & 0.099 & $2.227-2.621$ & $0.000 *$ \\
\hline & 5 & 3.014 & 1.136 & 0.102 & $2.812-3.216$ & $0.000 *$ \\
\hline \multirow{9}{*}{ Male } & 95 & -0.37 & 0.904 & 0.116 & $-0.602--0.138$ & $0.002^{*}$ \\
\hline & 85 & 0.176 & 0.897 & 0.115 & $-0.054-0.4058$ & 0.131 \\
\hline & 75 & 0.476 & 0.897 & 0.115 & $0.246-0.706$ & $0.000^{*}$ \\
\hline & 65 & 0.72 & 0.902 & 0.115 & $0.489-0.951$ & $0.000^{*}$ \\
\hline & 50 & 1.020 & 0.902 & 0.115 & $0.789-1.25$ & $0.000 *$ \\
\hline & 35 & 1.376 & 0.897 & 0.115 & $1.146-1.606$ & $0.000^{*}$ \\
\hline & 25 & 1.62 & 0.902 & 0.115 & $1.389-1.851$ & $0.000^{*}$ \\
\hline & 15 & 1.92 & 0.902 & 0.115 & $1.689-2.151$ & $0.000^{*}$ \\
\hline & 5 & 2.437 & 0.889 & 0.114 & $2.209-2.664$ & $0.000^{*}$ \\
\hline \multirow{9}{*}{ Female } & 95 & 0.073 & 1.105 & 0.139 & $-0.206-0.351$ & 0.603 \\
\hline & 85 & 0.766 & 1.098 & 0.138 & $0.489-1.043$ & $0.000 *$ \\
\hline & 75 & 1.119 & 1.086 & 0.137 & $0.845-1.392$ & $0.000 *$ \\
\hline & 65 & 1.429 & 1.094 & 0.138 & $1.154-1.705$ & $0.000^{*}$ \\
\hline & 50 & 1.835 & 1.083 & 0.136 & $1.562-2.107$ & $0.000 *$ \\
\hline & 35 & 2.235 & 1.083 & 0.136 & $1.962-2.507$ & $0.000^{*}$ \\
\hline & 25 & 2.535 & 1.083 & 0.136 & $2.262-2.807$ & $0.000^{*}$ \\
\hline & 15 & 2.912 & 1.076 & 0.136 & $2.641-3.183$ & $0.000 *$ \\
\hline & 5 & 3.573 & 1.072 & 0.135 & $3.303-3.843$ & $0.000 *$ \\
\hline
\end{tabular}

Table 3: The difference (in $\mathrm{mm}$ ) between the mean values of actual sum of mandibular permanent canine and first and second premolars of Nepalese Newar and those predicted from Moyers charts for the same subjects.

\begin{tabular}{|c|c|c|c|c|c|c|}
\hline Gender & Probability \% & Mean (Actual - Predicted) & SD & SEM & $95 \% \mathrm{Cl}$ & Sig. (2-tailed) \\
\hline \multirow{9}{*}{ Combined } & 95 & -1.032 & 0.866 & 0.078 & $-1.186-0.878$ & $0.000^{*}$ \\
\hline & 85 & -0.299 & 0.365 & 0.078 & $-0.452--0.145$ & $0.000^{*}$ \\
\hline & 75 & 0.132 & 0.877 & 0.787 & $-0.023-0.288$ & 0.096 \\
\hline & 65 & 0.468 & 0.872 & 0.078 & $0.313-0.623$ & $0.000^{*}$ \\
\hline & 50 & 0.939 & 0.883 & 0.079 & $0.782-1.096$ & $0.000^{*}$ \\
\hline & 35 & 1.389 & 0.872 & 0.078 & $1.234-1.544$ & $0.000^{*}$ \\
\hline & 25 & 1.727 & 0.883 & 0.079 & $1.570-1.884$ & $0.000^{*}$ \\
\hline & 15 & 2.166 & 0.873 & 0.078 & $2.011-2.321$ & $0.000 *$ \\
\hline & 5 & 2.890 & 0.885 & 0.079 & $2.733-3.047$ & $0.000^{*}$ \\
\hline \multirow{9}{*}{ Male } & 95 & -1.139 & 0.836 & 0.107 & $-1.353--0.925$ & $0.000^{*}$ \\
\hline & 85 & -0.399 & 0.849 & 0.109 & $-0.617--0.182$ & $0.001^{*}$ \\
\hline & 75 & 0.025 & 0.852 & 0.109 & $-0.194-0.243$ & 0.822 \\
\hline & 65 & 0.351 & 0.85 & 0.108 & $0.136-0.566$ & $0.002^{*}$ \\
\hline & 50 & 0.825 & 0.852 & 0.109 & $0.606-1.042$ & $0.000^{*}$ \\
\hline & 35 & 1.261 & 0.849 & 0.109 & $1.043-1.478$ & $0.000 *$ \\
\hline & 25 & 1.6 & 0.849 & 0.109 & $1.383-1.818$ & $0.000^{*}$ \\
\hline & 15 & 2.051 & 0.859 & 0.11 & $1.831-2.271$ & $0.000^{*}$ \\
\hline & 5 & 2.751 & 0.859 & 0.11 & $2.531-2.971$ & $0.000^{*}$ \\
\hline \multirow{9}{*}{ Female } & 95 & -0.929 & 0.889 & 0.112 & $-1.153--0.705$ & $0.000^{*}$ \\
\hline & 85 & -0.200 & 0.878 & 0.110 & $-0.421-0.020$ & 0.074 \\
\hline & 75 & 0.236 & 0.895 & 0.113 & $0.011-0.461$ & $0.040^{*}$ \\
\hline & 65 & 0.582 & 0.894 & 0.113 & $0.357-0.807$ & $0.000 *$ \\
\hline & 50 & 1.050 & 0.905 & 0.114 & $0.822-1.278$ & $0.000 *$ \\
\hline & 35 & 1.514 & 0.882 & 0.111 & $1.292-1.736$ & $0.000^{*}$ \\
\hline & 25 & 1.850 & 0.905 & 0.114 & $1.622-2.078$ & $0.000^{*}$ \\
\hline & 15 & 2.277 & 0.878 & 0.111 & $2.056-2.499$ & $0.000^{*}$ \\
\hline & 5 & 3.025 & 0.895 & 0.113 & $2.799-3.250$ & $0.000^{*}$ \\
\hline
\end{tabular}


Table 4: Regression parameters for prediction of buccal segment widths.

\begin{tabular}{|c|c|c|c|c|c|c|c|}
\hline Arch & Gender & $\mathbf{r}$ & $\mathbf{r}^{\mathbf{2}}$ & $\mathbf{a}$ & $\mathbf{B}$ & SEE & P value \\
\hline \multirow{3}{*}{ Maxillary Arch } & $\mathrm{M}$ & 0.59 & 0.35 & 12.159 & 0.453 & 0.81969 & $0.000^{*}$ \\
\cline { 2 - 8 } & $\mathrm{F}$ & 0.56 & 0.313 & 12.733 & 0.413 & 1.104 & $0.000^{*}$ \\
\cline { 2 - 8 } & $\mathrm{M}+\mathrm{F}$ & 0.61 & 0.378 & 11.707 & 0.464 & 0.984 & $0.000^{*}$ \\
\hline \multirow{3}{*}{ Mandibular Arch } & $\mathrm{M}$ & 0.81 & 0.647 & 3.903 & 0.763 & 0.74883 & $0.000^{*}$ \\
\cline { 2 - 9 } & $\mathrm{F}$ & 0.71 & 0.502 & 8.590 & 0.563 & 1.013 & $0.000^{*}$ \\
\cline { 2 - 9 } & $\mathrm{M}+\mathrm{F}$ & 0.77 & 0.589 & 6.534 & 0.653 & 0.903 & $0.000^{*}$ \\
\hline
\end{tabular}

\section{DISCUSSION}

Mixed dentition analysis is very important in orthodontic diagnosis and treatment planning as it helps to assess the degree of crowding or spacing that would occur by predicting the width of unerupted permanent canine and premolars. Various methods have been developed to predict width of unerupted canine and premolars among which Moyer's analysis is more commonly used.

This study confirmed other studies, $11,15-17$ that teeth in male were larger than that of female. Combined width of lower incisors, combined width of canine and premolars on both arches also showed statistically significant sexual dimorphism with males having greater value as found by Burhan et al and Diagne et $\mathrm{al}^{9},{ }^{9} 18$ whereas disagrees with Yuen et $\mathrm{al}^{19}$, who found combined lower incisors width to be greater in female than in male though the difference was not clinically significant. This may be due to racial variation in the mesiodistal width of teeth which has been confirmed by various studies. ${ }^{15,20-23}$

Both male and female showed higher correlation between sum of lower incisors width and sum of canine and premolars width in both arches, male having higher correlation than female and correlation was higher in mandible than in maxilla (for maxilla $r=0.59$ for male and 0.56 for female, for mandible $r=0.81$ for male and 0.71 for female, $p=<0.001$ ). Some studies have found higher correlation in female for both arches, 8 and some have found higher correlation in male. ${ }^{17,19}$

The difference between actual and predicted width of canine and premolars of male using Moyer's probability table was statistically significant in all probability levels except at $85 \%$ level for maxilla and $75 \%$ for mandible, and also for female it was statistically significant in all levels except at $95 \%$ level for maxillary and $85 \%$ level for mandibular canine and premolars. This shows that
Moyer's probability table can be used for estimating the combined width of canine and premolars for Nepalese Newars but at $85 \%$ probability level for maxilla and $75 \%$ for mandible in male and at $95 \%$ probability level for maxillary and $85 \%$ for mandible in female, despite the suggestion of Moyer to use the table at $75 \%$ probability level. Similarly, previous studies $8,9,16,17$ on different population also found the Moyer's table useful at probability levels other than $75 \%$.

Jaiswal et al10 found Moyer's prediction table to be inaccurate in Nepalese population, and Gyawali et $\mathrm{al}^{11}$ also found the table not applicable in Nepalese Brahmins and Chhetris. These studies compared their data with the Moyer's prediction table at 50\% and $75 \%$ probability levels only. Moyer's prediction table predicts the combined mesiodistal width of canines and premolars at various probability table. Although at $50 \%$ probability level values distribute normally towards spacing and crowding, Moyer has suggested to use $75 \%$ probability level since crowding is more serious problem and $75 \%$ level protects the clinician on safe side. Our study compared the data at all probability level and suggested that the table can be used in Nepalese Newar population at different probability level for male and female and for maxilla and mandible.

\section{CONCLUSION}

Moyer's probability table can be used to predict combined mesiodistal width population at $85 \%$ level for maxilla and at $75 \%$ level for mandible in male, at $95 \%$ probability level for maxilla and at $85 \%$ probability level for mandible in female. The regression equation derived in this study can also be used to predict the combined width of upper and lower permanent canine and premolars for both male and female Nepalese Newar.

\section{OJN}




\section{REFERENCES}

1. Proffit WR, Fields HWJ, Sarver DM. Contemporary Orthodontics. 4th ed. Canada: Mosby Elsevier; 2007.

2. Baral P. Prevalence of Malocclusion in Western Nepal. Orthod J Nepal. 2015;5(2):6-8.

3. Singh VP, Sharma A. Epidemiology of Malocclusion and Assessment of Orthodontic Treatment Need for Nepalese Children. Int Sch Res Not. 2014;2014:1-4

4. Carey CW. Diagnosis and case analysis in orthodontics. Am J Orthod Dentofac Orthop. 1952 Mar 1;38(3):149-61.

5. Hixon EH, Oldfather RE. estimation of sizes of cuspid and bicuspid by hixon. Angle Orthod. 1956;28(4):236-40.

6. Kloehn S. Guiding alveolar growth and eruption of teeth to reduce treatment time and produce a more balanced denture and face. [Internet]. Vol. 17, The Angle Orthodontist. 1947. p. 10-33.

7. Moyers RE. Handbook Of Orthodontics. 4th ed. United States of America: Year Book Medical Publishers, Inc; 1988.

8. Buwembo W, Kutesa A, Muwazi L, Rwenyonyi CM. Prediction of width of un-erupted incisors, canines and premolars in a Ugandan population: A cross sectional study. BMC Oral Health. 2012;12(1).

9. Burhan ASH, Nawaya FR. Prediction of unerupted canines and premolars in a syrian sample. Prog Orthod. 2014;15(1):1-8.

10. Jaiswal AK, Paudel KR, Shrestha SL, Jaiswal S. Prediction of space available for unerupted permanent canine and premolars in a Nepalese population. J Orthod. 2009;36:253-9.

11. Gyawali R, Shrestha BK, Yadav R. Mixed dentition space analysis among Nepalese Brahmins / Chhetris. BMC Oral Health. $2017 ; 1-7$.

12. Jaroontham J, Godfrey K. Mixed dentition space analysis in a Thai population. Eur J Orthod. 2000;22:127-34.

13. USA Central Intelligence Agency. The World Factbook 2010. New York Skyhorse cop; 2009.

14. Shrestha A, Pradhan D, Mehta $\vee$ V., Megha P. Proportionate value of mesiodistal dimension of maxillary lateral incisor with respect to maxillary anteriors in permanent dentition of Nepalese population. Int J Sci Res. 2017;6(11):173-4.

15. Shrestha RM. Measurement of mesio-distal tooth diameter of Nepalese permanent dentition. J Nep Dent Assoc. 2005;7(1):55-63. Abu Alhaija ESJ, Qudeimat MA. Mixed dentition space analysis in a Jordanian population : comparison of two methods. Int J Paediatr Dent. 2006;104-10.

16. Thimmegowda U, Sarvesh SG, Shashikumar HC, Kanchiswamy LN, Shivananda DH, Prabhakar AC. Validity of Moyers mixed dentition analysis and a new proposed regression equation as a predictor of width of unerupted canine and premolars in children. $\mathrm{J} C$ lin Diagnostic Res. 2015;9(8):ZC01-ZC06.

17. Diagne F, Diop-Ba K, Ngom Pl, Mbow K. Mixed dentition analysis in a Senegalese population: Elaboration of prediction tables. Am J Orthod Dentofac Orthop. 2003;124(2):178-83.

18. Yuen KK, Tang EL, So LL. Mixed dentition analysis for HongKong chinese. Angle Orthod. 1998;68(1):21-8.

19. Bishara SE, Garcia AF, Jakobsen JR, Fahl JA. Mesio-distal crown dimension in Mexico and US.pdf. Angle Orthod. 1986;315-23.

20. Singh SP, Goyal A. Mesiodistal crown dimensions of the permanent dentition in North Indian children. J Indian Soc Pedod Prev Dent. 2006;192-6.

21. Jain AK, Garg N, Singh J, Ansari A, B S. Mesiodistal crown dimensions of the permanent dentition of a North Indian population. Indian J Dent. 2011 Jun 1;2(2):16-20.

22. Santoro M, Ayoub ME, Arthur Pardi V, Cangialosi TJ. Mesiodistal Crown Dimensions and Tooth Size Discrepancy of the Permanent Dentition of Dominican Americans. Angle Orthod. 2000 Aug 1;70(4):303-7. 